The terrorist attack on 9/11/2001, and subsequent rescue, recovery, and service restoration of the World Trade Centre disaster site in New York City, created an unprecedented and unique occupational and environmental exposure that affected a large and diverse group of rescue workers and volunteers. The workers were exposed to a mixture of poorly characterised inhaled toxicants. A variety of acute and chronic respiratory illnesses have been reported among all exposed workers, which are the subject of large scale ongoing investigation and follow up. Our group created the WTC Chest Imaging Archive as a repository for more than 3500 chest CT scan studies in about 1700 WTC workers. We systematically assessed imaging abnormalities by means of the International CT Classification of Occupational and Environmental Respiratory Diseases. An examination of the first available chest CT scan for each subject $(n=1453)$ with complete available data, a median of 6.8 years after September 11, 2001 revealed that the most frequent recorded abnormalities were pleural abnormalities (parietal in $7.9 \%$ of the workers, and visceral in $12.8 \%$ of them), inhomogeneous attenuation (13.2\%), irregular/linear opacities (12.9\%), and emphysema (12.0\%). With regards to pleural abnormalities, although we found them across all 5 broad occupational groups, they were more frequent among construction labourers/asbestos handlers/building cleaners, most of whom were first-generation immigrants. Many of those abnormalities were not reported by clinical radiological readings. Visceral, but not parietal pleural changes were associated with mild pulmonary function impairment. Future studies will examine the evolution of imaging abnormalities, and add computerised quantitative CT scan to their assessment.

\section{C GERMAN EXPERIENCE USING ILO AND ICOERD-CODING IN THE SURVEILLANCE OF ASBESTOS- AND QUARTZ- EXPOSED WORKERS}

${ }^{1}$ Thomas Kraus, ${ }^{2}$ Kurt G Hering. ${ }^{1}$ RWTH Aachen Aachen, ${ }^{2}$ Knappschafstkrankenhaus Dortmund, Dortmund, Germany

10.1136/oemed-2018-ICOHabstracts.1263

Currently, there are about 60 to 70000 individuals on the surveillance program per year out of $>500000$ registered asbestos exposed persons, 240000 of them get an offer for medical examination, lung function and a chest X-ray every 3 years. Ca. $90 \%$ of the data (results of examination, lung function and conventional ILO-coding sheet) are transferred online.

Approximately $10 \%$ of the examined candidates gets a Low Dose Volume-HRCT. Lung cancer screening examinations in a high risk group have been started. Depending on the knowledge using the ILO International Classification of Radiographs of Pneumoconioses as universal standard for screening and health surveillance of individuals occupationally exposed to dusts, a standardised coding system has been demanded as obligatory not only for epidemiological purposes, but also as diagnostic criteria for occupational diseases.

The ILO classification is a standard surveillance tool, in use for more than 50 years in Germany. In 2005, a monograph 'International Classification of HRCT for Occupational and Environmental Respiratory Diseases - ICOERD' has been published. The work represented a consensus of international experts from Belgium, Finland, France, Germany, Great Britain, Japan and United States on a principal coding system along with reference films and imaging parameters. The reference films include examples with 5 and $1 \mathrm{~mm}$ slice thickness (incremental CT) for typical pleural and parenchymal findings.

Experienced radiologists will make the classification, or a CD-ROM with subjects' images will be sent to a B-Reader for classification. For coding purposes the reference-films are part of the classification. The reading results will be stored online at the Online-Portal-GVS-Server, which is provided by GVS Health Prophylaxis - a joint facility of the German Statutory Accident Insurance.

ILO-criteria for diagnosing asbestos related diseases are as follows: s, t, u irregular densities, more or equal 1/1 without and $1 / 0$ with inspiratory crackles or impairment of vital capacity, pleural thickening (plaque also unilateral at least $3 \mathrm{~mm}$ thickness, length $2 \mathrm{~cm}$, diffuse pleural thickening $2 \mathrm{a}$ both middle and lower field). ICOERD criteria for diagnosing asbestos related diseases are as follows: irregular and/or linear opacities in both lower and/or middle fields, sum profusion of at least 4 , any visible pleural thickening, visceral or pleural at least $1 \mathrm{a}$, with or without calcification, after exclusion of other causes. Similar criteria for silicosis will be presented.

\section{Conclusion}

- Taking into account the German experience with the coding system as part of guidelines for coding asbestosis, asbestosrelated pleural findings, silicosis and other occupational lung diseases, the HRCT-reference films are part of the standardised classification system (ICOERD).

- The documentation of reading and general surveillance data of dust exposed workers at a Online-Server meets the demand for displaying, reading and classifying subject data. Our German experiences with using the ILO and ICOERDclassification will be presented.

- HRCT-findings of occupational respiratory lung diseases should be classified using a standardised coding and scoring system. Reference films are provided to harmonise the description and documentation to achieve a reproducible score of the disease.

\section{ASSESSMENT OF JOB-RELATED ASTHMA CASES: OUR THREE-YEAR EXPERIENCE}

Ayşe Coşkun Beyan, Nur Şafak Alıcı, Arif Çımrın. Dokuz Eylul University Occupational Medicine Department, Izmir, Turkey

\subsection{6/oemed-2018-ICOHabstracts. 1264}

Introduction Work-related asthma (WRA) is one of the most common occupational diseases. There is no reliable statistical data for WRA in Turkey. In this study, we aimed to review diagnosing procedures and the characteristics of patients who were diagnosed with WRA at our clinic.

Methods Global Initiative for Asthma guideline was used to establish the diagnosis of asthma. Spirometric measurement, reversibility test and BPT were performed according to ATS criteria.Detailed occupational history was gained with questioning the job(s) starting from the first job, used material(s), duration, time, place properties chronologically and extensively. The relation of the complaints with job was defined. PEF measurements were performed for at least four times, for at least two weeks in working environment and at least two weeks during resting period. A graphic was createdusing the Microsoft Office Excel program taking the highest measurement of daily four sessions into account separately for resting 
and working periods. The PEF assessment graphic and job history were interpreted as; compatible with OA, compatible with WEA and technically not approved.

Result Two hundred and fourteen patients admitted to our clinic with WRA suspicion between November 2013 and June 2016. They were referred by an occupational health specialist, personal application, second- or third-line chest disease specialists [61 (28\%), 51 (23\%), and 102 (47\%) respectively]. Fiftyfour patients $(25 \%)$ were diagnosed with occupational asthma (OA), and $24(11 \%)$ with work exacerbated asthma (WEA), total 78 workers diagnosed with WRA. Twenty five $(32,1 \%)$ had allergic rhinitis. The most commonly used test were PEF monitoring and BPT respectively.

Discussion PEF monitoring, non-specific BPT and skin prick test for suitable cases would be sufficient besides occupational history and clinical properties for the diagnosis of WRA. PEF assessment, one of the most important tests for the diagnosis of WRA, must be performed.

\section{ACUTE IRRITANT-INDUCED ASTHMA CAUSED BY OZONE}

${ }^{1}$ Karl Færden*, ${ }^{1}$ Britt Grethe Randem, ${ }^{2}$ Per Arve Lier, ${ }^{3}$ Bjørn Granhus, 'Per Søstrand, 4,5Johny Kongerud. 'Department of Environmental and Occupational Medicine, Os/o University Hospital, Oslo, Norway; ${ }^{2}$ Humana Sandvika AS, Sandvika, Norway; ${ }^{3}$ Oslo Police District, Occupational Health Service, Oslo, Norway; ${ }^{4}$ Department of Respiratory Medicine, Rikshospitalet, Oslo University Hospital, Oslo, Norway; ${ }^{5}$ Faculty of Medicine, University of Oslo, Oslo, Norway

\subsection{6/oemed-2018-ICOHabstracts.1265}

Introduction Ozone-generating UV-lamps are used to remove unwanted grease from ventilation systems.

Irritant asthma after exposure to artificially produced ozone has been described at a Norwegian fish hatchery and a sewage plant, as well as in the Swedish paper industry.

We present cases that developed asthma after an accident with ozone-producing UV-systems in a restaurant kitchen.

Methods Case series Seven subjects that developed asthma were studied in relation to exposure, symptoms, medical history and clinical findings including lung function measurements, reversibility of airflow limitation and bronchial hyper responsiveness (BHR) to methacholine, both shortly after the accidental exposure and two years after the incident.

Result Out of a total number of 127 possibly ozone-exposed employees, 55 employees reported symptoms, and seven employees were diagnosed with occupational asthma after the incident. Six of these seven subjects had either positive reversibility and/or positive BHR tests.

Two years after cessation of exposure all seven subjects still needed treatment for asthma.

Three of the subjects had BHR despite the use of inhaled corticosteroids, all graded as 'very mild BHR'. FVC, FEV1, FEV1/FVC ratio and FeNO values were within normal range in all cases. None had long absence from work or needed emergency treatment in hospital for their asthma.

Discussion The adverse impact of ozone exposure on the airways is well known from epidemiological studies, where the focus has been on the negative health effects of ozone $\left(\mathrm{O}_{3}\right)$ in ambient air, especially in large cities. Commercial use of the ozone gas' odour absorbing and germ-killing properties has become more common in the last decade.

Accidents involving ozone gas from air purifiers with UVlamps may cause acute irritant asthma. There is a need for greater awareness in the use of ozone-generating devices.

\section{ASTHMA CONTROL AND WORK DISABILITY IN SUBJECTS PREVIOUSLY EVALUATED FOR WORK- RELATED ASTHMA WITH SPECIFIC INHALATION CHALLENGE}

Ilenia Folletti*, Umberto Giovannelli, Giulia Paolocci, Marco dell'Omo, Angela Gambelunghe, Nicola Murgia, Giacomo Muzi. Section of Occupational Medicine, Respiratory Diseases and Toxicology, University Of Perugia, Perugia, Italy

\subsection{6/oemed-2018-ICOHabstracts. 1266}

Background Currently available studies show that removal of subjects affected by occupational asthma from exposure does not always lead to an improvement in respiratory function. The cause of this is still unclear. The aim of our study was to evaluate in 2017 lung function and severity of asthma in subjects who underwent specific inhalation challenge (SIC) between 2006 and 2015 for work-related asthma.

Methods Clinical charts of 35 workers who underwent SIC have been evaluated. They were interviewed by telephone using a questionnaire to asses demographic data, respiratory symptoms and work disability. The severity of asthma was evaluated according to the GINA guidelines and asthma control was assessed by Asthma Control Questionnaire (ACQ). 18 workers agreed also to perform also spirometry.

Results 10 subjects had a positive SIC and 25 a negative SIC. Subjects with positive SIC had more frequently moderate persistent asthma treated with a combination of inhaler steroids and a bronchodilator (67\%) and those with negative SIC had more frequently intermittent asthma $(65 \%)$ treated with salbutamol as needed $(\mathrm{p}<0.05)$. The score of ACQ was greater among subjects with positive SIC than with negative SIC (11 vs $4, \mathrm{p}<0.05)$. Spirometry on 18 subjects showed among those with positive SIC a FEV1 lower (- 6\% in mean) and a RV greater $(+15 \%)$ compared to those with negative SIC. Subjects with positive SIC had more economic loss than subjects with negative SIC $(\mathrm{p}<0.05)$.

Conclusions Subjects who have had a positive SIC showed more severe asthmatic symptoms with lower asthma control despite current pharmacological therapy. They also had a higher RV than subjects with negative SIC. This could be a relevant parameter to evaluate in subjects with occupational asthma to improve asthma control.

\section{OCCUPATIONAL ASTHMA DUE TO EXPOSURE TO RHESUS MONKEY}

1,2S Keirsbilck*, 1,2E Adams, 1,3E Vandebroek, 'S Ronsmans, 1,4B Nemery. 'Clinic for occupational and environmental medicine, University Hospital Gasthuisberg, Leuven, Belgium; ${ }^{2}$ IDEWE, External Service for Prevention and Protection at Work, Heverlee, Belgium; ${ }^{3}$ Premed, External Service for Prevention and Protection at Work, Leuven, Belgium; ${ }^{4}$ Environment and Health, Department of Public Health and Primary Care, K.U.Leuven, Leuven, Belgium

\subsection{6/oemed-2018-ICOHabstracts. 1267}

Introduction A common cause of occupational asthma is exposure to animal proteins. Knowing this, laboratory workers are at risk when they work with laboratory animals (e.g. mice, rats, guinea pigs, rabbits). No reports were made up to date of allergy to rhesus monkey.

Methods We used all available information of the medical file of the patient. The patient explicitly authorised us to publish her case. 